\title{
Vermiculture as a biotechnological method of recultivation of disturbed lands in the post- mining system
}

\author{
Andrei Babenko ${ }^{1}$, Dmitrij Bezrukov', Saulet Karimova², Akmaral Mametova² and Ludmila \\ Zakonnova $^{3 *}$ \\ ${ }^{1}$ National Research Tomsk State University, 36 Lenina Avenue, Tomsk, Russia, 634050 \\ ${ }^{2}$ Mukhtar Auezov South Kazakhstan University, 5 Tauke khan avenue, 5 Shyment, The Republic of \\ Kazakhstan, 160012 \\ ${ }^{3}$ T.F. Gorbachev Kuzbass State Technical University, Belovo Branch, 652644бб Ilyica st. 32, \\ Belovo, Russia
}

\begin{abstract}
The article shows the prospects of using the technology of vermicomposting for the biological re-cultivation of disturbed mining areas. The valuable properties of vermicompost as a component of soilsubstituting mixtures for use in the re-cultivation of disturbed areas are considered. The expediency of using plant waste for the preparation of soil-substituting substrates is shown. The presence of special agrochemical properties of vermicompost obtained during the processing of plant waste (leaf litter) by the Eisenia fetida Savigny culture is experimentally established. The $\mathrm{pH}$ values and the content of calcium ions in the vermicompost based on poplar leaf litter were significantly higher than in the vermicompost based on horse manure - 7.61 vs. 6.98 and 112.3 vs. 83 mg-eq. / kg, respectively. Germination of wheat seeds on extracts from vermicompost obtained from poplar litter led to a statistically significant increase in the mass of the formed roots compared to seeds germinated on tap water.
\end{abstract}

\section{Introduction}

One of the most serious environmental problems of our time is the destruction of natural ecosystems as a result of human activity. In industrial areas, the most typical is the development of such negative processes as the destruction of soil cover, land pollution by industrial and household waste. So, as a result of coal mining in Kuzbass, about 100 thousand hectares of land were disturbed, of which a large area is occupied by overburden dumps [1].

When planning the reclamation of the territory disturbed as a result of industrial development, it is very important to choose the biological components of the re-cultivation process. When implementing the biological part of re-cultivation, soil mixtures, as well as plant objects, mainly fast-growing trees and shrubs, are traditionally used [2,3]. It is shown

\footnotetext{
${ }^{*}$ Corresponding author: belovo@kuzstu.ru
} 
that on the territory of Kuzbass on a production scale, forest re-cultivation is mainly carried out, and at the stage of scientific research there are works to improve the substrate of plant nutrition and create sustainable phytosystems in the reclaimed territories. In addition, biological re-cultivation of technogenic landscapes of Novokuznetsk was carried out, using sewage sludge [4].

Promising methods of soil-substituting soils (compost) preparing for reclamation are methods based on the use of biological objects in composting organic waste, in particular a number of earthworm species. It has been shown that adding approximately $33 \%$ of compost by volume to degraded soil improves its structure over time, while avoiding the financial and environmental costs associated with the use of expensive fertilizers [5]. Most often, worms of the genus Eisenia (E. foetida Sav., E. andrei Bouche) are used for vermicomposting. Representatives of the genus Eisenia are widely used in many countries for processing various organic waste, obtaining high-performance fertilizers and protein mass for multi-purpose use. The technology of vermicomposting is quite well developed; numerous studies have proved the possibility of processing by vermiculture a wide range of agricultural waste of animal and plant origin, leaf litter, as well as municipal waste, including sewage sludge [6-10]. It is also important that the technology of recycling organic residues using vermiculture is not associated with high costs for the construction of special sites and devices for vermicomposting.

In the process of waste transformation, worms are able to extract heavy metals from the substrate and accumulate in their body and convert them into bound forms that are inaccessible to plants, which allows expanding the range of applications of the final product of processing. This process proceeds without the use of chemical reagents, which makes biological disposal environmentally safe and does not lead to secondary contamination of surface reservoirs, ground underground waters and soils [11-12]. Unfortunately, to date, the use of vermicompost in land reclamation is practically not used, although there have been proposals to include the introduction of vermicompost in the biological part of land reclamation, the main producer of which is earthworms [1]. The experience of joint use of mycorrhizal fungi with earthworms to improve plant survival in the process of biological reclamation is also interesting [13].

The purpose of this work is to show the prospects of using the technology of vermicomposting for the restoration of disturbed mining areas.

\section{Materials and methods}

Most researchers have considered the use of vermicultivation on nitrogen-rich homogeneous substrates (cattle, horses, rabbits and poultry manure, sewage sludge). The preparation of these substrates requires additional labor and is not always economically justified. To date, the technology of vermicomposting has been poorly developed, where the basis of the processed mixture is relatively low-nitrogen plant waste. At the same time, it is the ubiquitous plant residues, due to their cheapness and general availability, that can serve as the main source of obtaining vermicompost intended for the restoration of disturbed areas.

We have been studying the possibility of processing organic waste with a high content of cellulose and, above all, leaf litter and mown lawn grass for a number of years. In comparative experiments, when composting various mixtures, the rate of processing of the composted mixture, the physical and chemical properties of the vermicompost, as well as its effect on the productivity of plants (Irgina wheat and Nevsky potatoes) were evaluated. The concentration of potassium ions, nitrates, and $\mathrm{pH}$ was determined in aqueous extracts from vermicompost by the potentiometric method. The content of $\mathrm{Ca} 2+$ ions in the studied extracts was determined by the complexometric method. 


\section{Results and discussion}

The rate of processing of compostable mixtures based on horse manure, leaf litter and mown lawn grass did not differ significantly. At a starting density of 50 adult E. foetida worms per 1 liter of compostable mixture, the process of complete processing of the compared compostable mixtures was completed 60-65 days after the start of the experiment in laboratory conditions (at a constant temperature of $23-24^{\circ} \mathrm{C}$ ) and $75-79$ days in open ground conditions with an air temperature fluctuation in the range of $14-26^{\circ} \mathrm{C}$.

A comparative study of the physical and chemical parameters of the vermicompost revealed that the vermicompost obtained from the fall of poplar leaves is significantly inferior to the vermicompost obtained from horse manure in terms of the electrical conductivity of the extracts and the concentration of potassium and nitrate ions. This distribution of nitrate anions in the studied samples is quite predictable, since leaf litter belongs to the group of nitrogen-depleted substrates. At the same time, the concentration of calcium ions and $\mathrm{pH}$ in samples of vermicompost from poplar leaf litter is significantly higher than in samples of vermicompost obtained from horse manure.

An important characteristic of vermicompost as an organic and mineral fertilizer is the quantitative ratio of "calcium/potassium". As can be seen from the table, the ratio of $\mathrm{Ca} 2+/ \mathrm{K}+$ is biased towards calcium, which is predominant in the samples of vermicompost obtained from a mixture of peat and poplar leaf litter. A clear predominance of potassium was characteristic of the samples of vermicompost obtained from horse manure.

Table 1. The physical and chemical parameters of the samples of the vermicompost produced while vermicomposting the peat-manure mixtures and the mixtures of peat and poplar leaf litter [14]

\begin{tabular}{|c|c|c|}
\hline Parameter & Peat+ Manure & Peat+Litter \\
\hline $\mathrm{pH}$ (water extract) & $6.9 \pm 0.17$ & $7.61 \pm 0.22$ \\
\hline $\begin{array}{c}\mathrm{EC}(\text { water extract), } \\
\mu \mathrm{S} \bullet \mathrm{cm}-1\end{array}$ & $1226.17 \pm 69.33$ & $1057.67 \pm 67.21$ \\
\hline $\mathrm{K}^{+}, \mathrm{mEq} / \mathrm{kg} \mathrm{DW}$ & $112.23 \pm 12.73$ & $72.98 \pm 3.74$ \\
\hline $\mathrm{NO}_{3}^{-}, \mathrm{mEq} / \mathrm{kg} \mathrm{DW}$ & $82.83 \pm 31.20$ & $5.58 \pm 3.66$ \\
\hline $\mathrm{Ca}^{2+}, \mathrm{mEq} / \mathrm{kg} \mathrm{DW}$ & $83.0 \pm 6.47$ & $112.33 \pm 9.24$ \\
\hline $\mathrm{Ca}^{2+} / \mathrm{K}^{+}$ & $0.74 \pm 0.07$ & $1.54 \pm 0.13$ \\
\hline
\end{tabular}

Note: $\mathrm{mEq}$ - milliequivalents/kg; DW - dry weight; EC - electroconductivity; means and $95-\%$ confidence intervals are given in the table.

These two variants were tested on plant objects in hydroponic experiments on the germination of cereals (wheat seeds) and the cultivation of isolated potato shoots.

The exposure of potato shoots on the vermicompost obtained from poplar litter resulted in a statistically significant, almost twofold increase in the relative root mass compared to both the control variant and the vermicompost obtained from horse manure. The relative weight of the roots formed during germination of Irgina wheat seeds on extracts from vermicompost obtained from horse manure and poplar leaf litter was as follows: tap water$14.33 \pm 4.93 \%$; on the basis of horse manure- $18.51 \pm 8.12$, on the basis of poplar litter$28.62 \pm 5.26 \%$.

Thus, germination of wheat seeds of the Irgina variety and isolated potato sprouts of the Nevsky variety on extracts from vermicompost obtained from poplar litter showed a statistically significant increase in the weight of the formed roots compared to sprouts and seeds germinated on tap water. For extracts from vermicompost obtained from horse manure, this effect was not observed $[14,15]$. 


\section{Conclusion}

Based on the data obtained, we can conclude that the extract from vermicompost obtained from leaf litter has a significant stimulating effect on the root formation of wheat seeds. In our opinion, the use of this biotechnological product as an organic fertilizer (during certain periods of ontogenesis) will have a positive impact on root formation and the formation of non-specific resistance of vegetation used in reclamation activities.

\section{References}

1. K. Nazjina, D. Davydov, Mining Information and Analytical Bulletin, 7, 401 (2014)

2. V. Ufimtsev, I. Belanov, O. Kupriyanov, Contemporary Problems of Ecology, 9 (1), $142(2016)$

3. J. Manakov, A. Kuprijanov, E3S Web of Conferences. 3th International Innovative Mining Symposium (Kemerovo, RF, October 3 - 5 2018), 41 (2018)

4. N. Makeeva, O. Neverova, KrasSAU Journal of Biology, 8, 77 (2008)

5. H. Heyman et al, International Journal of Environmental Research and Public Health, 16 (3971), 1 (2019)

6. S. Aggelides, L. Paraskevi, Bioresource Technology, 71 (3) (2000)

7. N. Arancon et al, European Journal of Soil Biology, 42, 65 (2006).

8. K. Judd et al, Pedobiologia, 39, 107 (1995)

9. R. Singh et al, Appl. Soil Ecol., 70, 48 (2013)

10. A. Yadav, V. Garg, Rev Environmental Science Biotechnology, 10, 243 (2011)

11. A. Neaman, S. Huerta, S. Sauvé, Ecotoxicol Environ Safety, 80, 386 (2012)

12. J. Zhang et al, Environ Science and Pollution Research, 26, 20949 (2019)

13. S. Ganihar, Restoration Ecology, 11 (4), 475 (2003)

14. A. Kurovskiy et al, Key Engineering Materials, 683, 519 (2016)

15. K. Petrochenko et al, Siberian Agricultural Journal, 3, 98 (2015) 